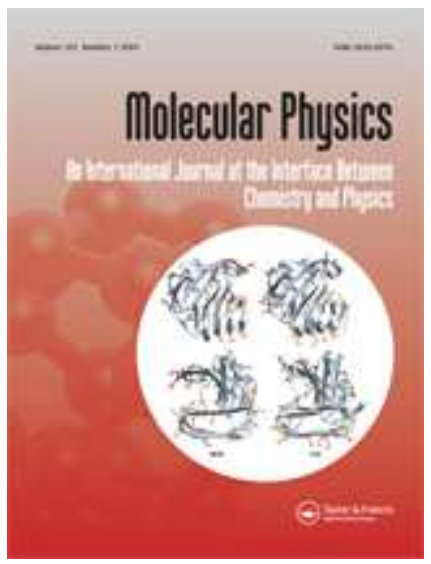

\title{
Implementation of Simple Logic Gates on Gold-Ammonia Bonding Patterns in Different Charge States
}

\begin{tabular}{|r|l|}
\hline Journal: & Molecular Physics \\
\hline Manuscript ID: & TMPH-2007-0341.R1 \\
\hline Manuscript Type: & Invited Article \\
\hline Date Submitted by the \\
Author: & 13 -Dec-2007 \\
\hline $\begin{array}{r}\text { Complete List of Authors: } \\
\text { Keywords: }\end{array}$ & $\begin{array}{l}\text { Remacle, Francoise; Université de Liège, Département de Chimie } \\
\text { Kryachko, Eugene; University of Liege, Chemistry }\end{array}$ \\
\hline & \\
\hline
\end{tabular}

\section{s scholarONE" \\ Manuscript Central}




\title{
Implementation of Simple Logic Gates on Gold-Ammonia Bonding
}

\section{Patterns in Different Charge States ${ }^{1}$}

\author{
E. S. Kryachko ${ }^{\dagger}$ and F. Remacle*, \\ Department of Chemistry, Bat. B6c, University of Liège, B-4000 Liège, Belgium \\ and Bogoliubov Institute for Theoretical Physics, Kiev-143, 03680 Ukraine
}

\section{Submitted to Molecular Physics: R. D. Levine Festschrift}

\begin{abstract}
We propose an approach for encoding the gold-ammonia bonding patterns on the conformational manifold of the $\mathrm{Au}_{\mathrm{n}} \mathrm{Z}-\left(\mathrm{NH}_{3}\right)_{\mathrm{m}}, \mathrm{Z}=0, \pm 1$, clusters in order to implement simple unary and binary logic gate operations. The gold-ammonia bonding patterns are governed by two different basic ingredients: the anchoring $\mathrm{Au}-\mathrm{N}$ bond and the nonconventional $\mathrm{N}-\mathrm{H} \cdot \cdots \mathrm{Au}$ hydrogen bond, and exhibit distinct characteristics as the charge of the cluster varies within $\mathrm{Z}=0, \pm 1$. The conformers of the small cluster, $\mathrm{Au}^{\mathrm{Z}}-\left(\mathrm{NH}_{3}\right)_{2}$, and of the nanometric size one, $\mathrm{Au}_{20} \mathrm{Z}$, are chosen as illustrative examples. The dependence of the bonding patterns on the overall charge state of the cluster allows to implement the logic gates NOT, FAN-OUT, AND, NAND, OR, NOR, INH, XOR, and XNOR and to identify the outputs using an IR readout protocol.
\end{abstract}

${ }^{1}$ Dedicated to Raphael D. Levine on the occasion of his $70^{\text {th }}$ birthday.

* Author for correspondence.

${ }^{\dagger}$ University of Liège and Bogoliubov Institute for Theoretical Physics; FAX: +32 (4) 366 3413; E-mail: eugene.kryachko@ulg.ac.be

¥Directeur de Recherches, FNRS (Belgium). University of Liège; FAX: +32 (4) 366 3413; E-mail: fremacle@ulg.ac.be 


\section{Introduction}

The implementation of logic gates on molecular systems is a field of intense activity. Early molecular realizations of logic gates relied on chemical and photochemical addressing in solution. [1-3] Faster implementations of logic gates based on optical addressing with laser pulses were proposed by Kompa and Levine [4] which led to further implementations of optical molecular logic machines up to a full adder and finite state machines by Levine and collaborators. [5-10] In parallel, several groups have shown that it is possible realize complex combinational logic circuits at the molecular scale, up to half and full addition or subtraction using various external perturbations, i.e., chemical, biochemical, photochemical, optical, electrochemical, electrical, to address the system, encode the inputs and perform the logic operations. [11-26]

We propose here another approach for implementing molecular logic gates. We suggest that logic operations can be implemented on the bonding patterns of the different conformers of a molecular system by inducing transitions between these patterns using external perturbation such as charge alternation or optical excitation. To illustrate this 'bond encoding' approach, we consider the gold-ammonia bonding patterns of the $\mathrm{Au}^{\mathrm{Z}}-\left(\mathrm{NH}_{3}\right)_{2}$ and of the $\mathrm{Au}_{20}{ }^{\mathrm{Z}}-\mathrm{NH}_{3}, \mathrm{Z}=0, \pm 1$, clusters that we recently computationally characterized. [27] As for other complexes between gold clusters and organic molecules that we have previously studied, [28-30] the bonding patterns of the gold ammonia clusters are governed by the Au-N anchoring and by the nonconventional $\mathrm{N}-\mathrm{H} \cdots \mathrm{Au}$ hydrogen bonding interactions. The nonconventional X-H $\cdots \mathrm{Au}(\mathrm{X}=\mathrm{N}, \mathrm{O}, \mathrm{F})$ hydrogen bonds act in synergy with the anchoring ones and have since been characterized experimentally in similar complexes. [31-33] The charge state of the interacting gold cluster significantly influences the interplay between the 
different gold-ammonia types of bonding and hence allows manipulating them. In this paper, we show how the bonding patterns of the complexes, $\mathrm{Au}^{\mathrm{Z}}-\left(\mathrm{NH}_{3}\right)_{2}$ and $\mathrm{Au}_{20} \mathrm{Z}-$ $\mathrm{NH}_{3}$, together with the alternation of their overall charge $\mathrm{Z}=0, \pm 1$ and optical excitation can be encoded into binary variables to implement simple logic gates. [34] Each binary input is encoded into a specific bond being 'on' or 'off'. The applied perturbation induces transitions between conformers characterized by different bonding patterns and these transitions implement the logic operations. In the specific implementation of binary gates discussed here, the output is determined by the energetic order of the conformer reached by the application of the perturbation. We propose to identify the conformers through their IR spectrum.

The bonding encoding approach has the potential to be more compact in terms of the encoding than other approaches to molecular logic, since a given family of complexes can possess a set of several addressable bonds. In the simple example of the $\mathrm{Au}^{\mathrm{Z}}-\left(\mathrm{NH}_{3}\right)_{2}, \mathrm{Z}=0, \pm 1$, family of conformers as well as for the nanometric size $\mathrm{Au}_{20} \mathrm{Z}-\mathrm{NH}_{3}$ complex that we use below, the bonding patterns are made of three kinds of bonds that interchange as the overall charge of the complex is modified.

Encoding classical bits into bonds is somewhat analogous to the approach known as vibrational quantum computing [35-38] in the sense that it requires addressable bonds (which each corresponds to a vibrational mode) as the inputs to the logic gate. The difference is that in our approach, the changes of the bonding patterns due to an external perturbation (charge alternation or optical excitation) implement the logic gate, not the transitions within the vibrational manifold induced by external IR laser pulses as is the case in vibrational quantum computing. 


\section{Bonding Patterns of $\mathrm{Au}^{0, \pm 1}-\left(\mathrm{NH}_{3}\right)_{2}$ Conformers}

As can be seen in figure 1, three different kinds of bonding interactions: the anchoring $\mathrm{Au}-\mathrm{N}$, nonconventional $\mathrm{N}-\mathrm{H} \cdots \mathrm{Au}$ and intramolecular $\mathrm{N}-\mathrm{H} \cdots \mathrm{N}$ hydrogen bondings, govern the stability of the two neutral, positively and negatively charged conformers, conformer I and conformer II, of $\mathrm{Au}^{\mathrm{Z}}-\left(\mathrm{NH}_{3}\right)_{2}(\mathrm{Z}=0, \pm 1)$. Two of these bonds interchange as the overall charge of the complex alternates from 0 to +1 . Larger complexes $\mathrm{Au}_{\mathrm{m}}{ }^{\mathrm{Z}}-\left(\mathrm{NH}_{3}\right)_{\mathrm{n}}$ have the potential to offer more possibilities in terms of bonding patterns.

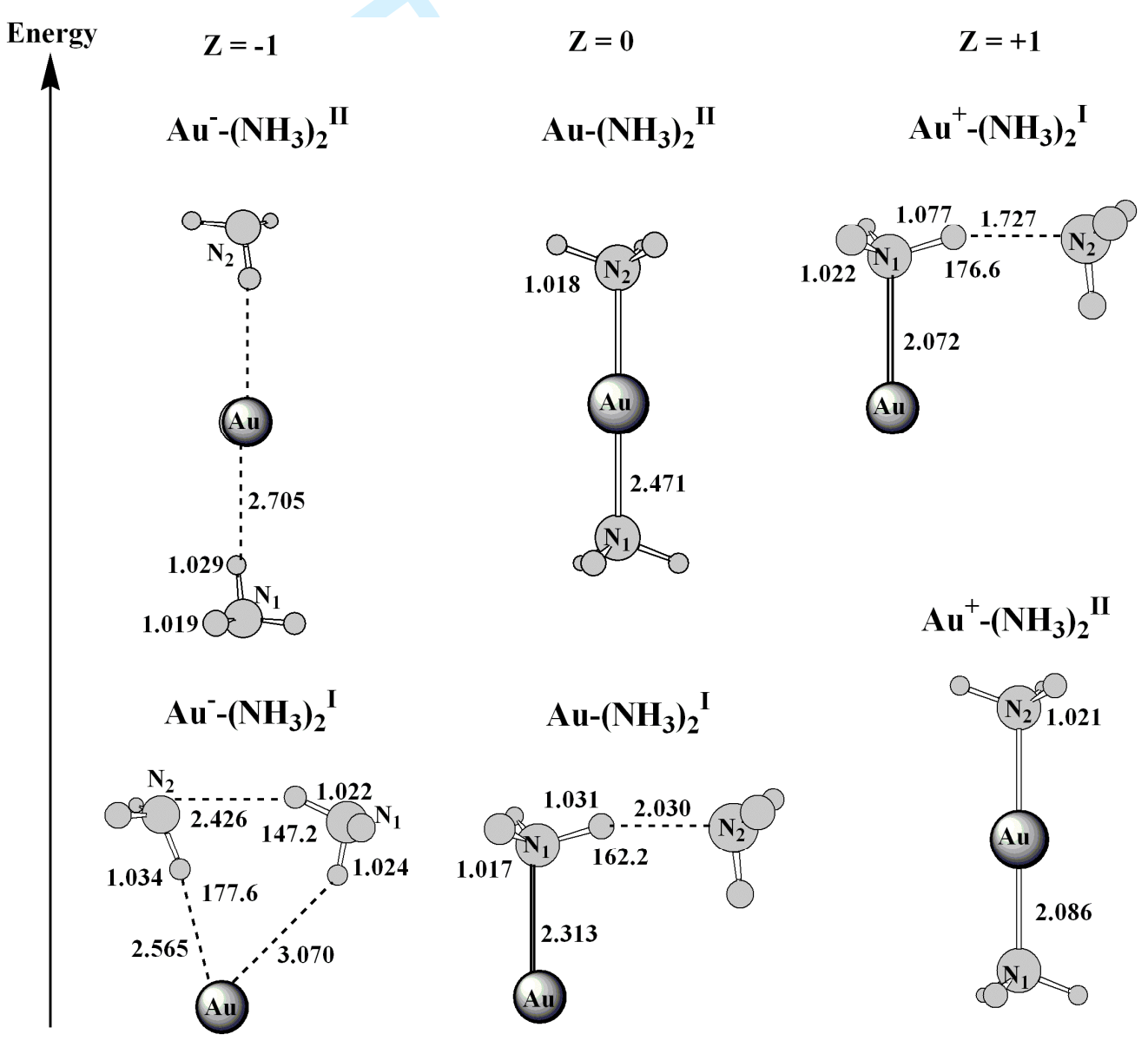

Figure 1. The bonding patterns of the two lowest energy conformers of $\mathrm{Au}^{\mathrm{Z}}-\left(\mathrm{NH}_{3}\right)_{2}$ computed for the charge state $\mathrm{Z}=+1,0,-1$. The computed geometrical, energetic, and spectroscopic properties of the conformers I and II can be found in ref. [27]. Details about the transition-state linkers and the computational methodology are given in Appendix. 
The energy difference between $\mathrm{Au}^{\mathrm{Z}}-\left(\mathrm{NH}_{3}\right)_{2}{ }^{\mathrm{I}}$ and $\mathrm{Au}^{\mathrm{Z}}-\left(\mathrm{NH}_{3}\right)_{2}{ }^{\mathrm{II}}$ varies from 4.3 $\mathrm{kcal} \cdot \mathrm{mol}^{-1}$ in the 0 -charge state to $43.6 \mathrm{kcal} \cdot \mathrm{mol}^{-1}$ in the cationic one. In contrast, the $\mathrm{Au}^{-}-\left(\mathrm{NH}_{3}\right)_{2}{ }^{\mathrm{I}}$ and $\mathrm{Au}^{-}-\left(\mathrm{NH}_{3}\right)_{2}{ }^{\mathrm{II}}$ are practically quasi-degenerate. [27] Details about the geometries of the transition states and the barrier heights between conformers I and II are given in the Appendix for the $\mathrm{Z}=0$ and $\mathrm{Z}=+1$ charge states. Taking the barrier heights into account, the transition between conformers I and II can be induced by an IR pulse with a carrier frequency of $\approx 2400 \mathrm{~cm}^{-1}$ while one needs a VIS carrier frequency of about $17500 \mathrm{~cm}^{-1}$ to induce the transition between the two conformers on the $\mathrm{Z}=-1$ potential energy surface (PES). In addition, conformers I and II have significantly different dipole moments and polarizabilities, the dipole moment of conformer II is zero due to symmetry. These different electrostatic properties can be used to select one or the other conformer in the logic schemes discussed in Section 3.2 below (see also discussion in Appendix). The alternation $Z \Rightarrow Z$ ' can be achieved either by using different metallic supporters or/and applied voltage, [39-42] by the optical 'negative ion - to neutral - to positive ion', NeNePo experimental setup [4346], or by resonant photoionization. [47]

For $\mathrm{Z}=0$, conformer $\mathrm{I}$ has one anchoring $\mathrm{Au}-\mathrm{N}_{1}$ bond and one conventional intermolecular $\mathrm{N}_{1}-\mathrm{H} \cdots \mathrm{N}_{2}$ H-bond, while the bonding patterns of conformer II consist of two anchoring bonds, $\mathrm{Au}-\mathrm{N}_{1}$ and $\mathrm{Au}-\mathrm{N}_{2}$. The same bonding patterns characterize the two conformers of the cation $(\mathrm{Z}=+1)$ but the energetic order of the conformers I and II is reversed by ionization. The bonding patterns of the negatively charged cluster are significantly different. The conformer I in the -1 charge state exhibits one conventional intermolecular $\mathrm{N}_{1}-\mathrm{H} \cdots \mathrm{N}_{2} \mathrm{H}$-bond and two nonconventional N-H..Au Hbonds. As a result, this conformer forms a cyclic structure. The three kinds of bonds 
in the bonding patterns of $\mathrm{Au}^{\mathrm{Z}}-\left(\mathrm{NH}_{3}\right)_{2}$ possess specific vibrational frequencies, listed in Table 1, that allow to uniquely characterize each conformer.

Table 1. The fundamental stretching vibrational frequencies (in $\mathrm{cm}^{-1}$ ) and $I R$ activities in parenthesis (in $\mathrm{km} \cdot \mathrm{mol}^{-1}$ ) of the six conformers of $\mathrm{Au}^{\mathrm{Z}}-\left(\mathrm{NH}_{3}\right)_{2}$ shown in Figure 1. $v_{\sigma}(\mathrm{H} \cdots \mathrm{X})$ and $v(\mathrm{~N}-\mathrm{H} \cdots \mathrm{X})$ designate, respectively, the fundamental H-bridge and $\mathrm{N}-\mathrm{H}$ stretching frequencies of the $\mathrm{N}-\mathrm{H} \cdots \mathrm{X}(\mathrm{X}=\mathrm{Au}, \mathrm{N})$ hydrogen bond.

\begin{tabular}{|c|c|c|c|c|}
\hline Charge & Conformer & $v(\mathrm{Au}-\mathrm{N})$ & $\begin{array}{l}v(\mathrm{~N}-\mathrm{H} \cdots \mathrm{Au}) \\
v_{\sigma}(\mathrm{H} \cdots \mathrm{Au})\end{array}$ & $\begin{array}{l}v(\mathrm{~N}-\mathrm{H} \cdots \mathrm{N}) \\
v_{\sigma}(\mathrm{H} \cdots \mathrm{N})\end{array}$ \\
\hline \multirow[t]{2}{*}{$\mathrm{Z}=0$} & $\mathrm{Au}-\left(\mathrm{NH}_{3}\right)_{2}{ }^{\mathrm{T}}$ & 314 & & $\begin{array}{l}3291(425) \\
198\end{array}$ \\
\hline & $\mathrm{Au}-\left(\mathrm{NH}_{3}\right)_{2}{ }^{\mathrm{II}}$ & $\begin{array}{l}v^{\text {sym }}=155 \\
v^{\text {asym }}=175\end{array}$ & & \\
\hline \multirow[t]{2}{*}{$\mathrm{Z}=+1$} & $\mathrm{Au}^{+}-\left(\mathrm{NH}_{3}\right)_{2}{ }^{\mathrm{II}}$ & $\begin{array}{l}v^{\text {sym }}=459 \\
v^{\text {asym }}=479\end{array}$ & & \\
\hline & $\mathrm{Au}^{+}-\left(\mathrm{NH}_{3}\right)_{2}{ }^{\mathrm{I}}$ & 493 & & $\begin{array}{l}2548(2335) \\
261\end{array}$ \\
\hline \multirow[t]{2}{*}{$Z=-1$} & $\mathrm{Au}^{-}-\left(\mathrm{NH}_{3}\right)_{2}{ }^{\mathrm{I}}$ & 20 & $\begin{array}{c}3253(467) \\
100 \\
\end{array}$ & $\begin{array}{l}3415(65) \\
118 \\
\end{array}$ \\
\hline & $\mathrm{Au}^{-}-\left(\mathrm{NH}_{3}\right)_{2}{ }^{11}$ & & $\begin{array}{l}v^{\text {sym }}=3345(558) \\
v^{\text {asym }}=3351(0) \\
v_{\sigma}^{\text {sym }}=84 \\
v_{\sigma}^{\text {asym }}=89\end{array}$ & \\
\hline
\end{tabular}

\section{Implementation of Unary and Binary Logic Gates}

\subsection{Unary NOT and One Bit FAN-OUT Gates on $\mathrm{Au}^{\mathrm{Z}}-\left(\mathrm{NH}_{3}\right)_{2}$}

The NOT gate operates on the conformational manifold of $\mathrm{Au}^{\mathrm{Z}}-\left(\mathrm{NH}_{3}\right)_{2}$ in the 0- charge state (see Figure 1). One possible implementation is to encode the input as a IR laser pulse that induces the transition between the ground state $|0\rangle$ (conformer I) and the lowest excited state |1〉 (conformer II). According to Figure 1, these conformers have a anchoring $\mathrm{Au}-\mathrm{N}_{1}$ bond in common and differ by the presence (conformer I) and the absence (conformer II) of an intermolecular $\mathrm{N}_{1}-\mathrm{H} \cdots \mathrm{N}_{2}$ bond, this bond flipping being accompanied by the formation of a Au- $\mathrm{N}_{2}$ bond in conformer II. To implement the NOT gate, we consider as the output the presence (bond 'on' $\equiv$ 
logic value ' 1 ') or the absence (bond 'off' $\equiv$ logic value ' 0 ') of the intermolecular $\mathrm{N}_{1}$ $\mathrm{H} \cdots \mathrm{N}_{2} \mathrm{H}$-bond whose computed vibrational frequency is equal to $3291 \mathrm{~cm}^{-1}$ (see Table 1). If the output is taken to be the presence or absence of the anchoring $\mathrm{Au}-\mathrm{N}_{2}$ bond, the IR excitation implements simultaneously a FAN-OUT or identity operation, in which the value of the bit is transmitted to a next step for a further logic operation. The truth tables of these two operations are given in Table 2. Note that the symmetric and asymmetric stretching vibrational frequencies describing the anchoring bonds in conformer II are equal to 155 and $175 \mathrm{~cm}^{-1}$, respectively (see Table 1). They are quite different for the $v\left(\mathrm{Au}-\mathrm{N}_{1}\right)$ frequency of conformer I $\left(314 \mathrm{~cm}^{-1}\right)$ so that both the NOT and the FAN-OUT outputs can be reliably distinguished by IR spectroscopy.

Table 2. Physical implementation of the NOT and the one bit FAN-OUT operation on the conformational manifold of $\mathrm{Au}-\left(\mathrm{NH}_{3}\right)_{2}$ in the 0 -charge state.

\begin{tabular}{|l|l|l|}
\hline $\begin{array}{l}\text { Input } \equiv \\
\text { IR excitation pulse }\end{array}$ & $\begin{array}{l}\mathrm{NOT} \equiv \\
\mathrm{N}_{1}-\mathrm{H} \cdots \mathrm{N}_{2}\end{array}$ & $\begin{array}{l}\text { FAN-OUT } \equiv \\
\mathrm{Au}-\mathrm{N}_{2}\end{array}$ \\
\hline 0 ('off') & 1 & 0 \\
\hline 1 ('on') & 0 & 1 \\
\hline
\end{tabular}

Another way to design a NOT gate, which uses the same manner of encoding the output as the two input binary gates discussed below is the following. The bond input is the presence or the absence of the $\mathrm{N}_{1}-\mathrm{H} \cdots \mathrm{N}_{2}$ bond and the output is the energetic ordering on the 0 -charge state conformational manifold: the lowest one 10$\rangle$ corresponds to the logic value ' 0 ' and the highest one $|1\rangle$ to the logic value ' 1 '. This leads to the implementation of the truth table given in Table 3. Within this implementation, the conformers are readout by a vibrational frequency that is specific for their bonding pattern, either the $v(\mathrm{Au}-\mathrm{N})$ or the $v_{\sigma}\left(\mathrm{H} \cdots \mathrm{N}_{2}\right)$ and $v\left(\mathrm{~N}_{1}-\mathrm{H} \cdots \mathrm{N}_{2}\right)$ modes.

Table 3. Alternative encoding for the implementation of a NOT gate on the 0-charge conformational manifold of $\mathrm{Au}-\left(\mathrm{NH}_{3}\right)_{2}$. 


\begin{tabular}{|l|l|}
\hline Input $\equiv$ & Output $\equiv$ \\
$\mathrm{N}_{1}-\mathrm{H} \cdots \mathrm{N}_{2}$ & Energetic ordering \\
\hline 1 & 0 \\
\hline 0 & 1 \\
\hline
\end{tabular}

\subsection{Implementation of Two Input Binary Logic Gates by Charge}

\section{Alternation on $\mathrm{Au}^{\mathrm{Z}}-\left(\mathrm{NH}_{3}\right)_{2}$}

Let us first consider the charge alternation $Z=0 \Rightarrow Z=+1$. In the logic schemes for two input binary gates, the output is the energetic ordering of the conformers on the $\mathrm{Z}=0$ and $\mathrm{Z}=+1$ PES's, as in Table 3 above. The first input (Input 1) corresponds to a specific bond within a given conformer on the neutral or positively charged PES. The bond will be set to the input value by optical excitation, IR for the $Z=0$ PES and VIS for the $Z=+1$ PES. The second input (Input 2) corresponds to the ionization process that induces charge alternation: $Z=0$ corresponds to the logic value ' 0 ', ionization is 'off' and $Z=+1$ to the logic value ' 1 ', ionization is 'on'. Keeping this encoding for the second input, we design simultaneously a XOR gate when the first input is the Au- $\mathrm{N}_{2}$ bond being 'off' or 'on' and a NOT-XOR (NXOR) gate when the first input is encoded in the bond $\mathrm{N}_{1}-\mathrm{H} \cdots \mathrm{N}_{2}$, as is shown in the implementation of the truth tables, Tables 4 and 5. Note that the first two lines of Table 4 correspond to the implementation of the NOT gate given in Table 3 above. The implementations of the XOR gate and of the NXOR are rather straightforward using this procedure, while it is typically harder to realize by more conventional molecular logic schemes because in a XOR gate when the two inputs are 'on' simultaneously, there should be a '0' output. [48, 49]

Table 4. Truth table for the implementation of the XOR gate of the neutral and positively charged conformers of $\mathrm{Au}-\left(\mathrm{NH}_{3}\right)_{2}$. The energetic order is encoded as follows. Neutral: $|0>\equiv \mathrm{I}| 1>,\equiv \mathrm{II} ; \mathrm{Z}=+1$ : $\left|0>\equiv \mathrm{II}^{+},\right| 1>\equiv \mathrm{I}^{+}$(see also Figure 1 ).

\begin{tabular}{|l|l|l|} 
Input $1 \equiv \mathrm{Au}-\mathrm{N}_{2}$ & Input $2 \equiv$ & Output $\equiv$ Input $1 \oplus$ Input 2 \\
\hline
\end{tabular} 


\begin{tabular}{|l|l|l|}
\hline $0 \equiv$ 'off', $1 \equiv$ 'on' & Ionization & $=$ Energetic ordering \\
\hline 0 & 0 & 0 (I on the $\mathrm{Z}=0$ PES) \\
\hline 1 & 0 & 1 (II on the $\mathrm{Z}=0$ PES) \\
\hline 0 & 1 & 1 (I on the $\mathrm{Z}=+1$ PES) \\
\hline 1 & 1 & 0 (II on the $\mathrm{Z}=+1$ PES) \\
\hline
\end{tabular}

Table 5. Truth table for the implementation of the NXOR gate on the neutral and positively charged conformers of $\mathrm{Au}-\left(\mathrm{NH}_{3}\right)_{2}$. Same encoding of the energetic order as in Table 4.

\begin{tabular}{|l|l|l|}
\hline $\begin{array}{l}\text { Input } 1 \equiv \mathrm{N}_{1}-\mathrm{H} \cdots \mathrm{N}_{2} \\
0 \equiv \text { 'off', } 1 \equiv \text { 'on' }\end{array}$ & $\begin{array}{l}\text { Input } 2 \equiv \\
\text { Ionization }\end{array}$ & $\begin{array}{l}\text { Output }= \\
\text { Energetic ordering }\end{array}$ \\
\hline 0 & 0 & 1 (II on the $\mathrm{Z}=0$ PES) \\
\hline 1 & 0 & 0 (I on the $\mathrm{Z}=0$ PES) \\
\hline 0 & 1 & 0 (II on the $\mathrm{Z}=+1$ PES) \\
\hline 1 & 1 & 1 (I on the $\mathrm{Z}=+1$ PES) \\
\hline
\end{tabular}

The two conformers I and II in the $\mathrm{Z}=-1$ charge state are quasi-degenerate (see Figure 1). In terms of logic encoding of the output, they both correspond to the same logic value that we can define either as ' 0 ' or ' 1 '. This allows to implement the family of two input binary gates where three values of the output are identical, such as the OR and NOR, AND and NAND and the INH gates. Together with the XOR and NXOR binary gates and the NOT unary gate above, they allow to build various combinations of 'complete' sets of gates for binary functions, also known as universal sets of gates. By 'complete' or 'universal', it is meant that any Boolean function can be computed by building a combinational circuit made of gates belonging to the complete set only.[34, 50] The NAND gate and the NOR gate are universal gates, and the sets $\{$ AND, XOR, NOT $\}$ or $\{$ AND, OR, NOT $\}$ form complete sets. The choice of the complete set used for building circuits depends on the set of gates that are physically available. NAND gate circuits require to being able to implement a single 
kind of two input gate only, but they require a lot of concatenation and wiring and for these reasons, they are not necessarily the most efficient combinational circuits at the molecular level.

In the implementation of the NOR and OR, AND and NAND and the INH gates, the first input is the $\mathrm{N}_{1}-\mathrm{H} \cdots \mathrm{N}_{2}$ bond that can be 'on' or 'off' and the second input is the charge alternation as for the XOR and the NXOR gates above, but now between the $Z=0$ and $Z=-1$ charge states. For the charge alternation, one can use to complementary encodings: (i) The transition from $Z=0 \Rightarrow Z=-1$ is performed by electron attachment, that is 'electron attachment off' means logic value ' 0 ' and to be in the $\mathrm{Z}=0$ charge state and 'electron attachment on' means logic value ' 1 ' and to be in the $\mathrm{Z}=-1$ state. The complementary logic encoding is (ii) by electron detachment, that is, 'electron detachment off' means to be in the $Z=-1$ state with logic value 0 and 'electron detachment on' to be in the $\mathrm{Z}=0$ charge state with logic value ' 1 '. We also use complementary encodings for input 1 , the $\mathrm{N}_{1}-\mathrm{H} \cdots \mathrm{N}_{2}$ bond that can be 'on' or 'off' is associated either with logic values ' 1 ' and ' 0 ', or with ' 0 ' and ' 1 ' respectively.

For the NOR gate implementation, we use the bond $\mathrm{N}_{1}-\mathrm{H} \cdots \mathrm{N}_{2}$ for input 1, with the encoding bond 'on' corresponds to logic value ' 1 ' and bond 'off' to logic value ' 0 '. The second input is an electron attachment, so that the logic value ' 0 ' corresponds to the neutral, $\mathrm{Z}=0$, conformers and the logic value ' 1 ' to the negatively charged, $\mathrm{Z}=$ -1 ones. The NOR implementation is given in Table 6. Both quasi-degenerate conformers of the $\mathrm{Z}=-1$ charge state are encoded into the logic value ' 0 '.

Table 6. Implementation of the truth table of a NOR gate on the neutral and negatively charged conformers of $\mathrm{Au}-\left(\mathrm{NH}_{3}\right)_{2}$.

\begin{tabular}{|l|l|l|}
\hline $\begin{array}{l}\text { Input } 1 \equiv \mathrm{N}_{1}-\mathrm{H} \cdots \mathrm{N}_{2} \\
0 \equiv \text { 'off', } 1 \equiv \text { 'on' }\end{array}$ & $\begin{array}{l}\text { Input } 2 \equiv \\
\text { Electron attachment }\end{array}$ & $\begin{array}{l}\text { Output } \equiv \\
\text { Energetic ordering }\end{array}$ \\
\hline 0 & 0 & 1 (II on the $\mathrm{Z}=0$ PES) \\
\hline
\end{tabular}




\begin{tabular}{|l|l|l|}
\hline 1 & 0 & 0 (I on the $Z=0$ PES) \\
\hline 0 & 1 & 0 (II on the $Z=-1$ PES) \\
\hline 1 & 1 & 0 (I on the $Z=-1$ PES) \\
\hline
\end{tabular}

For implementing an AND gate, we use the complementary logic encoding for bond input. The logic value ' 1 ' is associated with the $\mathrm{N}_{1}-\mathrm{H} \cdots \mathrm{N}_{2}$ as being 'off' and the logic value ' 0 ' with the bond being 'on'. Input 2 is an electron detachment (ionization). The logic value ' 1 ' is associated with electron detachment from $\mathrm{Z}=-1$ so that the complex is in the 0 -charge state and the logic value ' 0 ' when electron detachment is 'off' and the complex remains in -1-charge state (see Table 7 below), the two quasi-degenerate conformers in the -1-charge state correspond to the logic value ' 0 '.

Table 7. Implementation of an AND gate on the negatively charged and neutral Au$\left(\mathrm{NH}_{3}\right)_{2}$ conformers.

\begin{tabular}{|l|l|l|}
\hline $\begin{array}{l}\text { Input } 1 \equiv \mathrm{N}_{1}-\mathrm{H} \cdots \mathrm{N}_{2} \\
0 \equiv \text { 'on', } 1 \equiv \text { 'off' }\end{array}$ & $\begin{array}{l}\text { Input } 2 \equiv \\
\text { Electron detachment }\end{array}$ & $\begin{array}{l}\text { Output } \equiv \\
\text { Energetic ordering }\end{array}$ \\
\hline 0 & 0 & 0 (I on the $\mathrm{Z}=-1$ PES) \\
\hline 1 & 0 & 0 (II on the $\mathrm{Z}=-1$ PES) \\
\hline 0 & 1 & 0 (I on the $\mathrm{Z}=0$ PES) \\
\hline 1 & 1 & 1 (II on the $\mathrm{Z}=0$ PES) \\
\hline
\end{tabular}

The OR logic gate is obtained by using the same encoding for input 1: the logic value ' 1 ' is associated with the $\mathrm{N}_{1}-\mathrm{H} \cdots \mathrm{N}_{2}$ as being 'off' and the logic value ' 0 ' with the bond as being 'on'. Input 2 is electron attachment as for the NOR gate (Table 6). In addition, the two quasi-degenerate negatively charged conformers are associated with the logic value ' 1 '. The implementation of the truth table is given in Table 8.

Table 8. Implementation of the truth table for a OR gate on the neutral and negatively charged conformers of $\mathrm{Au}-\left(\mathrm{NH}_{3}\right)_{2}$. 


\begin{tabular}{|l|l|l|}
\hline $\begin{array}{l}\text { Input } 1 \equiv \mathrm{N}_{1}-\mathrm{H} \cdots \mathrm{N}_{2} \\
0 \equiv \text { 'on', } 1 \equiv \text { 'off' }\end{array}$ & $\begin{array}{l}\text { Input } 2 \equiv \\
\text { Electron attachment }\end{array}$ & $\begin{array}{l}\text { Output } \equiv \\
\text { Energetic ordering }\end{array}$ \\
\hline 0 & 0 & 0 (I on the $\mathrm{Z}=0$ PES) \\
\hline 1 & 0 & 1 (II on the $\mathrm{Z}=0$ PES) \\
\hline 0 & 1 & 1 (I on the $\mathrm{Z}=-1$ PES) \\
\hline 1 & 1 & 1 (II on the $\mathrm{Z}=-1$ PES) \\
\hline
\end{tabular}

In order to implement the NAND gate, we use the same encoding of inputs 1 and 2 as in the implementation of the NOR gate (Table 6): $\mathrm{N}_{1}-\mathrm{H} \cdots \mathrm{N}_{2}$ being 'off' corresponds to the logic value ' 0 ' and 'on' to the logic value ' 1 '. Input 2 is encoded as electron detachment. The difference with the encoding of the NOR gate is that the logic value ' 1 ' is associated to the two quasi-degenerate negatively charged conformers. The implementation of the truth table of the NAND gate is given in Table 9.

Table 9. Implementation of the truth table for a NAND gate on the neutral and negatively charged conformers of $\mathrm{Au}-\left(\mathrm{NH}_{3}\right)_{2}$.

\begin{tabular}{|l|l|l|}
\hline $\begin{array}{l}\text { Input } 1 \equiv \mathrm{N}_{1}-\mathrm{H} \cdots \mathrm{N}_{2} \\
0 \equiv \text { 'off', } 1 \equiv \text { 'on' }\end{array}$ & $\begin{array}{l}\text { Input } 2 \equiv \\
\text { Electron detachment }\end{array}$ & $\begin{array}{l}\text { Output } \equiv \\
\text { Energetic ordering }\end{array}$ \\
\hline 0 & 0 & 1 (II on the $\mathrm{Z}=-1$ PES) \\
\hline 1 & 0 & 1 (I on the $\mathrm{Z}=-1$ PES) \\
\hline 0 & 1 & 1 (II on the $\mathrm{Z}=0$ PES) \\
\hline 1 & 1 & 0 (I on the $\mathrm{Z}=0$ PES) \\
\hline
\end{tabular}

The INH gate is important for implementing the borrow bit of a half subtraction because the only pair of inputs that leads to an output $\equiv 1$ is the $(0,1)$ pair while all the other pairs lead to an output $\equiv 0$. The INH can be implemented using for input 1 the encoding $\mathrm{N}_{1}-\mathrm{H} \cdots \mathrm{N}_{2}$ 'off' means logic value ' 0 ' and 'on' means logic value 
' 1 ' and electron detachment for input 2 . The logic value ' 0 ' is assigned to both quasidegenerate conformers in the negative charge state. This leads to the following implementation for the truth table (Table 10).

Table 10. Implementation of the truth table for a INH gate on the neutral and negatively charged conformers of $\mathrm{Au}-\left(\mathrm{NH}_{3}\right)_{2}$.

\begin{tabular}{|l|l|l|}
\hline $\begin{array}{l}\text { Input } 1 \equiv \mathrm{N}_{1}-\mathrm{H} \cdots \mathrm{N}_{2} \\
0 \equiv \text { 'off', } 1 \equiv \text { 'on' }\end{array}$ & $\begin{array}{l}\text { Input } 2 \equiv \\
\text { Electron detachment }\end{array}$ & $\begin{array}{l}\text { Output } \equiv \\
\text { Energetic ordering }\end{array}$ \\
\hline 0 & 0 & 0 (II on the $\mathrm{Z}=-1$ PES) \\
\hline 1 & 0 & 0 (I on the $\mathrm{Z}=-1$ PES) \\
\hline 0 & 1 & 1 (II on the $\mathrm{Z}=0$ PES) \\
\hline 1 & 1 & 0 (I on the $\mathrm{Z}=0$ PES) \\
\hline
\end{tabular}

\section{3. Generalization to a nanometric size cluster: $\mathrm{Au}_{20}-\mathrm{NH}_{3}$}

The lowest conformer of $\mathrm{Au}_{20}$ has a $T_{d}$ shape with $\mathrm{Au}$ atoms exhibiting different Mulliken charge and coordination number depending on whether they are apex atoms $\left(\mathrm{Au}^{\mathrm{a}}\right)$ or edge atoms $\left(\mathrm{Au}^{\mathrm{e}}\right)$. [27, 51, 52] The anchoring of a $\mathrm{NH}_{3}$ molecule on this nanometric size cluster leads to the same kinds of bonding patterns as those identified for the smaller gold clusters which can also be manipulated by alternation of the overall charge of the cluster. The implementation of logic gates proposed in Section 3.2 for the small $\mathrm{Au}-\left(\mathrm{NH}_{3}\right)_{2}$ can therefore be generalized to nanometric size clusters. The latter have the advantage that they can be anchored on a surface and therefore addressed electrically. The anchoring on a surface is also essential for the concatenation of the logic gates. In this Section, we present preliminary results for the realization of some of the two input binary gates that can be implemented with the anchoring of a single $\mathrm{NH}_{3}$ molecule on $\mathrm{Au}_{20}$ : the OR/NOR, AND/NAND and INH gates, as well as the unary NOT gate. We start by briefly summarizing the bonding 
patterns of the neutral and negatively charged conformers of $\mathrm{Au}_{20}{ }^{\mathrm{Z}}-\left(\mathrm{NH}_{3}\right), \mathrm{Z}=0,-1$ that are relevant for logic gate implementation.

The two lowest energy conformers of the $\mathrm{Au}_{20}{ }^{\mathrm{Z}}-\left(\mathrm{NH}_{3}\right)(\mathrm{Z}=0,-1)$ are shown in Figure 2. Their energy ordering on the PES exhibits the same trends as the negatively charged and neutral conformers of the $\mathrm{Au}-\left(\mathrm{NH}_{3}\right)_{2}$ cluster shown in Figure 1 above. The two, lowest in energy, negatively charged conformers of $\mathrm{Au}_{20}-\mathrm{NH}_{3}$ are quasi degenerate (the computed energy difference is $0.2 \mathrm{kcal} \cdot \mathrm{mol}^{-1}$ ). On the other hand, the two lowest neutral conformers are separated by $6.3 \mathrm{kcal} \cdot \mathrm{mol}^{-1}$, which corresponds to an IR optical excitation. The two conformers of the neutral charged state have distinct bond patterns. The lowest conformer, conformer I, exhibits a Au-N anchor bond where the $\mathrm{Au}$ atom is a 'apex' $\mathrm{Au}$ atom, $\mathrm{Au}^{\mathrm{a}}$, of the $\mathrm{Au}_{20} T_{d}$ cluster, with a three-fold coordination and Mulliken charge of -0.42 , whereas in conformer II, the $\mathrm{Au}-\mathrm{N}$ bond is weaker as it involves a six-fold coordinated $\mathrm{Au}$ 'edge' atom, $\mathrm{Au}^{\mathrm{e}}$, of Mulliken charge 0.09. As a result, the two kinds of anchoring bonds can be distinguished by IR spectroscopy. The vibrational frequency of the $\mathrm{Au}^{\mathrm{a}}-\mathrm{N}$ bond is 257 $\mathrm{cm}^{-1}$ (75) (IR activities are given in parentheses in $\mathrm{km} \cdot \mathrm{mol}^{-1}$ ) while that of the $\mathrm{Au}^{\mathrm{e}}-\mathrm{N}$ bond of conformer II is $220 \mathrm{~cm}^{-1}$ (24). This difference in the vibrational frequencies of the Au-N bonds in conformers I and II is mirrored by the N-H vibrational frequencies of the $\mathrm{NH}_{3}$ molecule which are $3483 \mathrm{~cm}^{-1}$ (15), $3614 \mathrm{~cm}^{-1}$ (25), 3614 $\mathrm{cm}^{-1}$ (25) and $3485 \mathrm{~cm}^{-1}$ (3), $3622 \mathrm{~cm}^{-1}$ (20), $3623 \mathrm{~cm}^{-1}$ (16) respectively. In addition, the computed dipole moments of the neutral conformers I and II of $\mathrm{Au}_{20^{-}}$ $\mathrm{NH}_{3}$ are $9.6 \mathrm{D}$ (conformer I) and $6.6 \mathrm{D}$ (conformer II), which would allow to select one or the other using their orientation properties.

As is the case for $\mathrm{Au}^{-}-\left(\mathrm{NH}_{3}\right)$ (see Figure 1), the bonding patterns of the negatively charged $\mathrm{Au}_{20}{ }^{-}-\left(\mathrm{NH}_{3}\right)$ differ significantly from the conformers of the neutral 
charge state. In one of the quasi degenerate negatively charged conformer (conformer I), the anchoring of the $\mathrm{NH}_{3}$ molecule leads to the opening of the $\mathrm{Au}_{20}$ pyramid and to the formation of a cyclic structure where the $\mathrm{NH}_{3}$ molecule is linked to the $\mathrm{Au}_{20}$ cluster by an anchoring Au-N involving an edge Au atom and by a non-conventional $\mathrm{N}-\mathrm{H} \cdots \mathrm{Au}$ bond. In the quasidegenerate conformer II, the anchoring of the $\mathrm{NH}_{3}$ molecule is through a $\mathrm{Au}^{\mathrm{a}}-\mathrm{N}$ bond. The two conformers, while energetically quasi degenerate, can be distinguished by the presence or not of the vibrational frequency corresponding to the non-conventional N-H..Au bond which falls at $3342 \mathrm{~cm}^{-1}$ and is red shifted by $142 \mathrm{~cm}^{-1}$ compared to the $\mathrm{N}-\mathrm{H}$ frequency of conformer II.

The bonding patterns and the energetics of the negatively charged and neutral $\mathrm{Au}_{20}-\mathrm{NH}_{3}$ cluster lead to the same schemes as those proposed in Section 3.2 above for the implementation of the family of two input binary gates where three values of the output are identical, i.e., the OR/NOR, AND/NAND and INH gates. In all implementations based on $\mathrm{Au}_{20}-\mathrm{NH}_{3}$, we use for input 1 the anchoring bond $\mathrm{Au}^{\mathrm{a}}-\mathrm{N}$ instead of the intramolecular $\mathrm{N}_{1}-\mathrm{H} \cdots \mathrm{N}_{2}$ bond for $\mathrm{Au}-\left(\mathrm{NH}_{3}\right)_{2}$ and this is the only difference with the schemes summarized in Tables 6 to 10 in Section 3.2 above. The $A u^{a}-N$ bond is experimentally distinguishable from the $A u^{e}-N$ one. It is 'on' in conformer I and 'off' in conformer II of the $\mathrm{Z}=0$ charge state, the same is true of the $\mathrm{Z}=-1$ charge state with the difference that the bonding pattern of conformer II has a cyclic character. For input 2, we use the electron attachment or electron detachment processes as in Section 3.2 above. The output is the energetic order of the conformers on the PES's $\mathrm{Z}=0$ and $\mathrm{Z}=-1$, taking into account that conformers $\mathrm{I}$ and II on the $\mathrm{Z}=$ -1 PES are quasi-degenerate, and therefore must be encoded into the same binary value, either 1 or 0 , also as in Section 3.2 above. Note however that they can be selectively prepared as is explained in the Appendix. 
With the specific encodings: $\mathrm{Au}^{\mathrm{a}}-\mathrm{N}$ bond 'on' is associated with logic value ' 1 ' and 'off' with logic value ' 0 ' for input 1 and for input 2, the electron attachment process ('on' $\equiv 1$ and 'off' $\equiv 1$ ), we obtain a NOR gate whose truth table implementation is completely analogous to the NOR implementation proposed in Table 6. By reversing the encoding of the $\mathrm{Au}^{\mathrm{a}}-\mathrm{N}$ bond, that is, attributing logical value ' 1 ' when the bond is 'off' and logical value ' 0 ' when the bond is 'on', and encoding the two quasi degenerate $Z=-1$ conformers into logical value 1 for the output, one gets an implementation of a OR gate analogous to that of Table 8 . For the AND, NAND and INH implementations, we use the electron detachment process for input 2 and the truth table implementations are analogous to Tables 7, 9 and 10 respectively, where of course the $\mathrm{N}_{1}-\mathrm{H} \cdots \mathrm{N}_{2}$ bond needs to be replaced by the $\mathrm{Au}^{\mathrm{a}}-\mathrm{N}$ one. Note to conclude that one can also implement a NOT gate on neutral charge state of $\mathrm{Au}_{20}-\mathrm{NH}_{3}$ using the $\mathrm{Au}^{\mathrm{a}}-\mathrm{N}$ instead of the $\mathrm{N}_{1}-\mathrm{H} \cdots \mathrm{N}_{2}$ bond in Table 3 above. On the other hand, the implementation of the XOR and NXOR gates (Tables 4 and 5) is not possible with only one $\mathrm{NH}_{3}$ molecule anchored on $\mathrm{Au}_{20}$. Work is in progress to find the adequate nanometric size cluster that will allow such implementations. 
$Z=-1$

$$
\mathrm{Au}_{20}-\mathrm{NH}_{3}^{\mathrm{I}}
$$

$$
\mathrm{Z}=0
$$

$$
\mathrm{Au}_{20}-\mathrm{NH}_{3}{ }^{\mathrm{II}}
$$
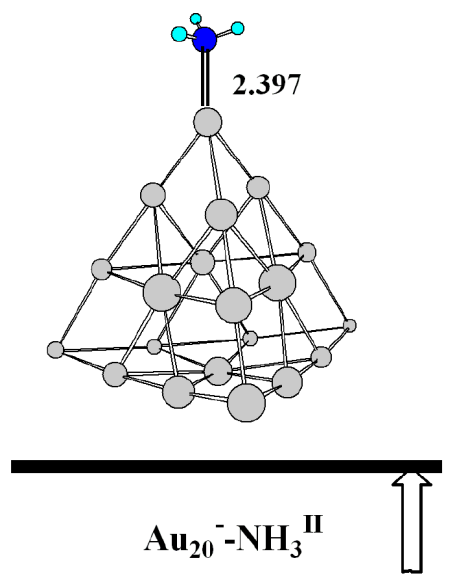

$0.2 \mathrm{kcal} / \mathrm{mol}$
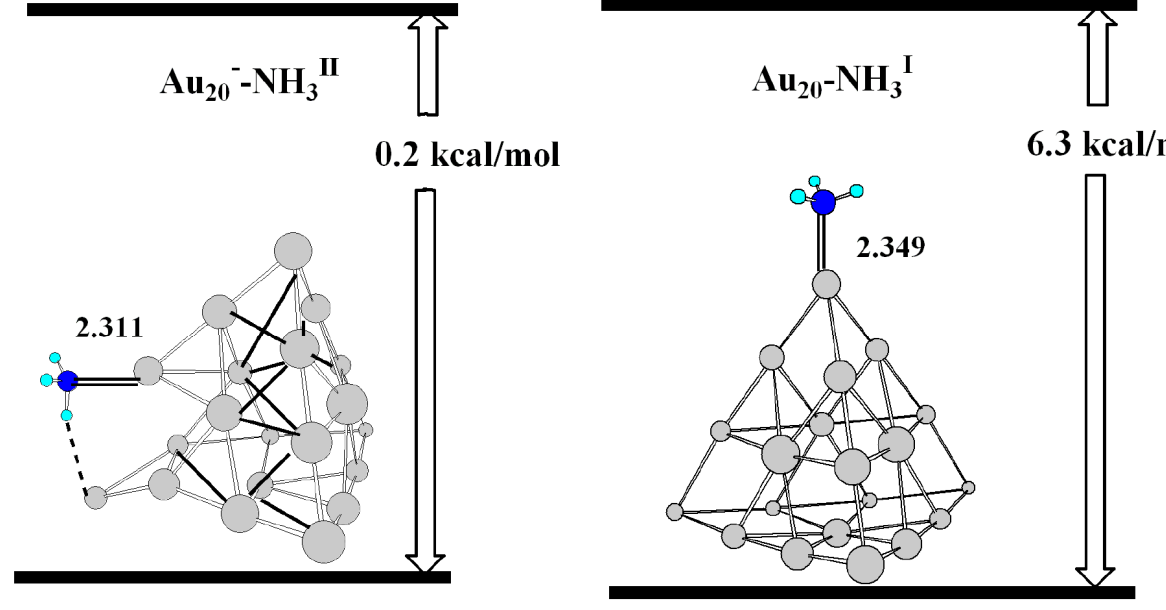

Figure 2. The bonding patterns of the two lowest energy conformers of $\mathrm{Au}_{20}{ }^{\mathrm{Z}}-\left(\mathrm{NH}_{3}\right)$ computed for the charge states $\mathrm{Z}=-1$ and 0 . The computational methodology is outlined in the Appendix. The computed geometrical, energetic, and spectroscopic properties of the conformers I and II can be found in ref. [27], as well as those of the $\mathrm{Z}=+1$ conformers, not shown here. 


\section{Concluding Remarks}

We have shown that the computed bonding patterns of a small cluster like $\mathrm{Au}-$ $\left(\mathrm{NH}_{3}\right)_{2}$, complemented by charge alternation and optical excitation processes, can be used for implementing several logic gates such as NOT, XOR, NXOR, OR, NOR, AND, NAND and INH, that form various combinations of complete (or universal) sets of gates for designing the combinational circuits corresponding Boolean functions. We also give preliminary results that show that most of these logic gate implementations can be generalized to nanometric size clusters, such as $\mathrm{Au}_{20}-\mathrm{NH}_{3}$. Several issues need to be addressed before practical implementations of the bond encoding approach proposed here can be realized. Among them is the design of precise encoding procedures based on experimental measurements and of concatenation schemes for transferring the output of a gate to another gate, either between two clusters or within the same cluster. More work is also needed to check whether the bond encoding approach can be useful for the implementation of finite state machines $[53,54]$ using bond encoding for the memory unit.

While the implementation schemes that we propose are purely theoretical and may not be easily realized experimentally, the bond encoding approach appears to be rather general, versatile and transferable to larger size nanometric gold clusters on which various small organic molecules anchors using the interplay between anchoring $\mathrm{Au}-\mathrm{X}(\mathrm{X}=\mathrm{O}, \mathrm{N}, \mathrm{F})$, the nonconventional $\mathrm{X}-\mathrm{H} \cdot \cdots \mathrm{Au}$ hydrogen bond and the conventional intermolecular $\mathrm{X}-\mathrm{H} \cdots \mathrm{X}$ bonds. The fact that the different kinds of bonding patterns of gold-ammonia clusters identified for small clusters are also present in the nanometric size cluster $\mathrm{Au}_{20}-\mathrm{NH}_{3}$ is promising and suggests that concatenation schemes might be devised since the larger clusters can be anchored on a surface and electrically, as well as optically addressed. 


\section{Acknowledgements}

This work was partially supported by the EC FET-OPEN STREP Project MOLDYNLOGIC and by FRFC.2465.06 (Belgium). We thank the reviewer for valuable comments and suggestions.

\section{Appendix: Computational Methodology and Some Computational Notes}

The complexes between $\mathrm{Au}^{\mathrm{Z}}-\left(\mathrm{NH}_{3}\right)_{2}$ are computationally studied by means of the GAUSSIAN 03 package of quantum chemical programs. [55] The Kohn-Sham self-consistent field formalism with the hybrid density functional B3LYP potential is used in conjunction with the basis sets $6-311++\mathrm{G}(\mathrm{d}, \mathrm{p})$ for ammonia and the energyconsistent $19-\left(5 s^{2} 5 p^{6} 5 d^{10} 6 s^{1}\right)$ valence electron relativistic effective core potential (RECP) developed by Ermler, Christiansen and co-workers with the primitive basis set $(5 s 5 p 4 d)$ [56] for gold. All geometrical optimizations are performed with the keywords 'Tight' and 'Int $=$ UltraFine'. The unscaled harmonic vibrational frequencies and zero-point vibrational energies (ZPVE) are also calculated in order to distinguish minima from saddle structures.

For each charge state $\mathrm{Z}=0, \pm 1$, the total PES of the $\mathrm{Au}^{\mathrm{Z}}-\left(\mathrm{NH}_{3}\right)_{2}$ complex consists of two conformers only, $\mathrm{Au}^{\mathrm{Z}}-\left(\mathrm{NH}_{3}\right)_{2}{ }^{\mathrm{I}}$ (conformer I) and $\mathrm{Au}^{\mathrm{Z}}-\left(\mathrm{NH}_{3}\right)_{2}{ }^{\mathrm{II}}$ (conformer II), the geometries of which are shown in Figure 1. These conformers are characterized by different vibrational frequencies as summarized in Table 1 . They can be selected according to their orientation properties since the conformer II has a zero dipole moment due to symmetry, whereas the conformer I has a finite one equal to 5.3 D. Conformers I and II differ also by their polarizabilities, namely 79.6 vs. 227.3. On the PES with a given $\mathrm{Z}$, they are interconnected by the transition-state structures 
shown in Figure A for the 0- and +1-charge states, which are relevant to the logic gates discussed in Section 3.2. The binding energy of the conformer I in the +1 charge state amounts to $125.6 \mathrm{kcal} \cdot \mathrm{mol}^{-1}$ with respect to the dissociation limit $\mathrm{Au}^{+}+$ $2 \mathrm{NH}_{3}$, whereas that of the conformer II, taken relative to the dissociation asymptote $\mathrm{Au}^{+}+\left(\mathrm{NH}_{3}\right)_{2}$, is equal to $80.1 \mathrm{kcal} \cdot \mathrm{mol}^{-1}$. From these considerations, a VIS pulse could be used to induce the transitions I $\rightarrow$ II as well as II $\rightarrow$ I for the $\mathrm{Z}=+1$ charge state. For the $\mathrm{Z}=0$ one, an IR pulse of about $2400 \mathrm{~cm}^{-1}$ can be used for both ways.

The B3LYP results for the $\mathrm{Au}^{\mathrm{Z}}-\left(\mathrm{NH}_{3}\right)_{2}$ complex reported in this work (see alos ref [27]) were compared with the other commonly used exchange-correlation density functional potentials, such as PBEPBE, BLYP, and PW91PW91 (see e. g. [55]), together with the second-order perturbation Møller-Plesset frozen-core method (MP2). The results are summarized in Table A. A good correlation between the different methods is found for the geometric, spectroscopic, and energetic characteristics, except for the MP2 overestimation of the $\Delta \mathrm{E}(\mathrm{I}-\mathrm{II})$ in the 0 -charge state comparing with the B3LYP one.

Table A. The geometric, spectroscopic, and energetic characteristics of the $\mathrm{Au}^{\mathrm{Z}}$ $\left(\mathrm{NH}_{3}\right)_{2}$ complex obtained by means of the exchange-correlation density functional

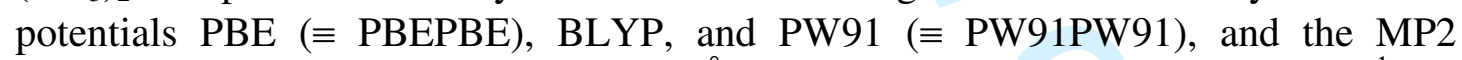
method. The bond lengths are given in $\AA$, bond angles in ${ }^{\circ}$, frequencies in $\mathrm{cm}^{-1}$, IR activities in parentheses in $\mathrm{km} \cdot \mathrm{mol}^{-1}$, and the ZPVE-corrected energy difference in $\mathrm{kcal} \cdot \mathrm{mol}^{-1}$. The hydrogen atom of the $\mathrm{N}_{1} \mathrm{H}_{3}$ molecule (the subscript 1 indicates the nitrogen atom) which participates in the hydrogen bonding with another $\mathrm{N}_{2} \mathrm{H}_{3}$ molecule (the subscript 2 indicates the nitrogen atom) is designated by $\mathrm{H}^{\prime}$, whereas that involved in the hydrogen bonding with $\mathrm{Au}$ by H'. Free hydrogens of both ammonia molecules are simply designated by $\mathrm{H}$. 


\begin{tabular}{|c|c|c|c|c|c|c|c|c|c|c|c|c|}
\hline & \multicolumn{4}{|c|}{$\mathrm{Z}=0$} & \multicolumn{4}{|c|}{$\mathrm{Z}=+1$} & \multicolumn{4}{|c|}{$Z=-1$} \\
\hline & PBE & BLYP & PW91 & MP2 & PBE & BLYP & PW91 & MP2 & PBE & BLYP & PW91 & MP2 \\
\hline \multicolumn{13}{|l|}{ Conformer I } \\
\hline $\mathrm{R}\left(\mathrm{Au}-\mathrm{N}_{1}\right)$ & 2.272 & 2.330 & 2.268 & 2.206 & 2.048 & 2.081 & 2.047 & 2.055 & & & & \\
\hline $\mathrm{R}\left(\mathrm{N}_{1}-\mathrm{H}^{\prime}\right)$ & 1.045 & 1.041 & 1.044 & 1.027 & 1.118 & 1.102 & 1.118 & 1.058 & 1.031 & 1.031 & 1.030 & 1.018 \\
\hline $\mathrm{R}\left(\mathrm{N}_{1}-\mathrm{H}\right)$ & 1.024 & 1.025 & 1.023 & 1.016 & 1.030 & 1.030 & 1.029 & 1.020 & & & & \\
\hline $\mathrm{R}\left(\mathrm{N}_{1}-\mathrm{H}^{\prime \prime}\right)$ & & & & & & & & & 1.036 & 1.035 & 1.035 & 1.021 \\
\hline $\mathrm{R}\left(\mathrm{H}^{\prime} \cdots \mathrm{N}_{2}\right)$ & 1.950 & 2.018 & 1.941 & 2.045 & 1.611 & 1.681 & 1.606 & 1.796 & 2.401 & 2.490 & 2.392 & 2.447 \\
\hline$\angle \mathrm{N}_{1} \mathrm{H}^{\prime} \mathrm{N}_{2}$ & 156.7 & 162.6 & 156.5 & 158.7 & 176.8 & 175.9 & 176.8 & 178.1 & 144.7 & 145.5 & 144.4 & 144.6 \\
\hline $\mathrm{R}\left(\mathrm{N}_{2}-\mathrm{H}^{\prime \prime}\right)$ & & & & & 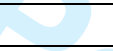 & & & & 1.050 & 1.046 & 1.049 & 1.028 \\
\hline $\mathrm{R}\left(\mathrm{H}^{\prime}{ }^{\prime} \cdots \mathrm{Au}\right)$ & & & & & & & & & 2.431 & 2.532 & 2.411 & 2.575 \\
\hline$\angle \mathrm{N}_{2} \mathrm{H}^{\prime \prime} \mathrm{Au}$ & & & & & & & & & 178.2 & 178.2 & 178.3 & 176.7 \\
\hline$v\left(\mathrm{Au}-\mathrm{N}_{1}\right)$ & 284 & 257 & 286 & 350 & 514 & 488 & 517 & 496 & & & & \\
\hline$v_{\sigma}\left(H^{\prime} \cdots N_{2}\right)$ & 220 & 196 & 223 & 204 & 290 & 268 & 294 & 300 & 123 & 111 & 125 & 125 \\
\hline$v\left(\mathrm{~N}_{1}-\mathrm{H}^{\prime} \cdots \mathrm{N}_{2}\right)$ & $\begin{array}{l}3103 \\
(544)\end{array}$ & $\begin{array}{l}3145 \\
(499)\end{array}$ & $\begin{array}{l}3098 \\
(547)\end{array}$ & $\begin{array}{l}3389 \\
(309)\end{array}$ & $\begin{array}{l}2059 \\
(2921)\end{array}$ & $\begin{array}{c}2243 \\
(2489)\end{array}$ & $\begin{array}{l}2050 \\
(2931)\end{array}$ & $\begin{array}{l}2865 \\
(1793)\end{array}$ & $\begin{array}{l}3277 \\
(128)\end{array}$ & $\begin{array}{l}3284 \\
(90)\end{array}$ & $\begin{array}{l}3275 \\
(140)\end{array}$ & $\begin{array}{l}3491 \\
(72)\end{array}$ \\
\hline$v_{\sigma}\left(\mathrm{H}^{\prime} \cdots \mathrm{Au}\right)$ & & & & & & & & 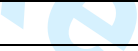 & 106 & 100 & 107 & 101 \\
\hline$v\left(\mathrm{~N}_{2}-\mathrm{H}^{\prime}{ }^{\prime} \cdots \mathrm{Au}\right)$ & & & & & & & & 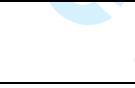 & $\begin{array}{l}3040 \\
(593)\end{array}$ & $\begin{array}{l}3086 \\
(514) \\
\end{array}$ & $\begin{array}{l}3032 \\
(600)\end{array}$ & $\begin{array}{l}3379 \\
(402)\end{array}$ \\
\hline Conformer II & & & & & & & & & +2 & 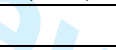 & & \\
\hline $\begin{array}{l}\mathrm{R}\left(\mathrm{Au}-\mathrm{N}_{1}\right)= \\
\mathrm{R}\left(\mathrm{Au}-\mathrm{N}_{2}\right)\end{array}$ & 2.328 & 2.436 & 2.342 & 2.300 & 2.072 & 2.100 & 2.071 & 2.063 & & & & \\
\hline $\mathrm{R}\left(\mathrm{N}_{1}-\mathrm{H}\right)$ & 1.029 & 1.028 & 1.028 & 1.020 & 1.028 & 1.029 & 1.027 & 1.020 & & & & \\
\hline \multicolumn{13}{|l|}{$\mathrm{R}\left(\mathrm{N}_{1}-\mathrm{H}^{\prime \prime}\right)$} \\
\hline $\mathrm{R}\left(\mathrm{H}^{\prime}{ }^{\prime} \cdots \mathrm{Au}\right)$ & & & & & & & & & 2.535 & 2.659 & 2.512 & 2.681 \\
\hline $\mathrm{R}\left(\mathrm{N}-\mathrm{H}^{\prime \prime}\right)$ & & & & & & & & & 1.043 & 1.041 & 1.043 & 1.024 \\
\hline $\mathrm{R}(\mathrm{N}-\mathrm{H})$ & & & & & & & & & 1.027 & 1.029 & 1.026 & 1.015 \\
\hline \multirow[t]{2}{*}{$v^{\text {sym,asym }}(\mathrm{Au}-\mathrm{N})$} & 172 & 157 & 177 & 178 & 470 & 446 & 472 & 486 & 96 & 84 & 99 & 88 \\
\hline & 255 & 200 & 246 & 254 & 485 & 464 & 488 & 499 & 101 & 89 & 104 & 94 \\
\hline $\begin{array}{l}v^{\text {sym,asym }} \\
\left(\mathrm{N}-\mathrm{H}^{\prime}, \cdots \mathrm{Au}\right)\end{array}$ & & & & & & & & & $\begin{array}{l}3160 \\
(815) \\
3170 \\
(0)\end{array}$ & $\begin{array}{l}3185 \\
(711) \\
3192 \\
(0)\end{array}$ & $\begin{array}{l}3155 \\
(857) \\
3165 \\
(0)\end{array}$ & $\begin{array}{l}3448 \\
(406) \\
3451 \\
(51)\end{array}$ \\
\hline$\Delta \mathrm{E}(\mathrm{I}-\mathrm{II})$ & -2.0 & -2.4 & -1.9 & -7.3 & 44.4 & 42.2 & 44.7 & 46.9 & 0.1 & 0.6 & 0.1 & -0.5 \\
\hline
\end{tabular}

URL: http://mc.manuscriptcentral.com/tandf/tmph 

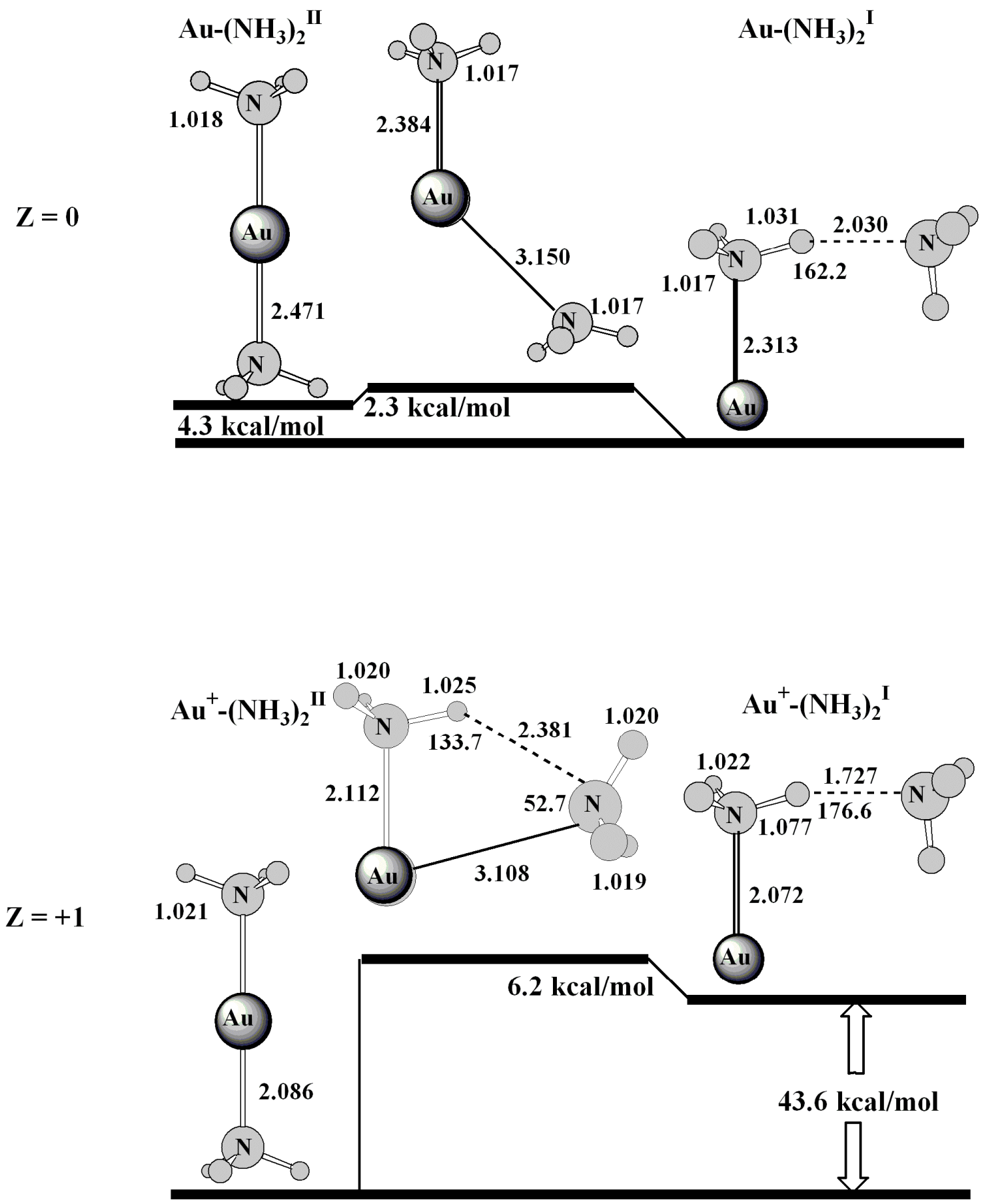

Figure A. The transition-state linkers between the conformers I and II for $\mathrm{Z}=0,+1$. Their transition frequencies are equal to $113 \mathrm{i}$ and $147 \mathrm{i} \mathrm{cm}^{-1}$, respectively. The bond lengths are given in $\AA$ and bond angles in ${ }^{\circ}$. 


\section{References}

[1] A. Credi, V. Balzani, S. J. Langford, and J. F. Stoddart, J. Am. Chem. Soc. 119, 2679 (1997).

[2] A. P. deSilva, H. Q. N. Gunaratne, and C. P. McCoy, J. Am. Chem. Soc. 119, 7891 (1997).

[3] A. P. Desilva, H. Q. N. Gunaratne, and C. P. McCoy, Nature 364, 42 (1993).

[4] K. L. Kompa, and R. D. Levine, Proc. Natl. Acad. Sci. U.S.A. 98, 410 (2001).

[5] T. Witte, C. Bucher, F. Remacle, D. Proch, K. L. Kompa, and R. D. Levine, Angew. Chemie Int. Ed. 40, 2512 (2001).

[6] F. Remacle, S. Speiser, and R. D. Levine, J. Phys. Chem. A 105, 5589 (2001).

[7] D. Steinitz, F. Remacle, and R. D. Levine, ChemPhysChem. 3, 43 (2002).

[8] F. Remacle, R. Weinkauf, D. Steinitz, K. L. Kompa, and R. D. Levine, Chem. Phys. 281, 363 (2002).

[9] F. Remacle, I. Willner, and R. D. Levine, ChemPhysChem. 6, 1239 (2005).

[10] F. Remacle, R. Weinkauf, and R. D. Levine, J. Phys. Chem. A 110, 177 (2006).

[11] P. R. Ashton, R. Ballardini, V. Balzani, A. Credi, K. R. Dress, E. Ishow, C. J. Kleverlaan, O. Kocian, J. A. Preece, N. Spencer, J. F. Stoddart, M. Venturi, and S. Wenger, Chem.-Eur. J. 6, 3558 (2000).

[12] V. Balzani, A. Credi, F. M. Raymo, and J. F. Stoddart, Angew. Chem. Int. Ed. 39, 3349 (2000).

[13] A. P. deSilva, and N. D. McClenaghan, J. Am. Chem. Soc. 122, 3965 (2000).

[14] J. C. Ellenbogen, and J. C. Love, Proc. IEEE 88, 386 (2000).

[15] F. M. Raymo, Adv. Mat. 14, 401 (2002).

[16] S. Ami, M. Hliwa, and C. Joachim, Chem. Phys. Lett. 367, 662 (2003).

[17] M. N. Stojanovic, and D. Stefanovic, J. Am. Chem. Soc. 125, 6673 (2003).

[18] I. Duchemin, and C. Joachim, Chem. Phys. Lett. 406, 167 (2005).

[19] R. Baron, O. Lioubashevski, E. Katz, T. Niazov, and I. Willner, Angew. Chem. Int. Ed. 45, 1572 (2006).

[20] X. Chen, Y. F. Wang, Q. Liu, Z. Z. Zhang, C. H. Fan, and L. He, Angew. Chem. Int. Ed. 45, 1759 (2006).

[21] D. Margulies, G. Melman, and A. Shanzer, J. Am. Chem. Soc. 128, 4865 (2006).

[22] T. Niazov, R. Baron, E. Katz, O. Lioubashevski, and I. Willner, Proc. Natl. Acad. Sci. U.S.A. 103, 17160 (2006).

[23] M. de Sousa, B. de Castro, S. Abad, M. A. Miranda, and U. Pischel, Chem. Comm. 2051 (2006).

[24] L. F. O. Furtado, A. D. P. Alexiou, L. Goncalves, H. E. Toma, and K. Araki, Angew. Chem. Int. Ed. 45, 3143 (2006).

[25] R. Ballardini, P. Ceroni, A. Credi, M. T. Gandolfi, M. Maestri, M. Semararo, M. Venturi, and V. Balzani, Adv. Funct. Mat. 17, 740 (2007).

[26] D. Margulies, C. E. Felder, G. Melman, and A. Shanzer, J. Am. Chem. Soc. 129, 347 (2007).

[27] E. S. Kryachko, and F. Remacle, J. Chem. Phys. 127, 194305 (2007).

[28] E. S. Kryachko, A. Karpfen, and F. Remacle, J. Phys. Chem. A 109, 7309 (2005).

[29] E. S. Kryachko, and F. Remacle, J. Phys. Chem. B 109, 22746 (2005).

[30] E. S. Kryachko, and F. Remacle, Nano. Lett. 5, 421 (2005).

[31] H. Nuss, and M. Jansen, Angew. Chem. Int. Ed. 45, 4369 (2006). 
[32] H. Schneider, A. D. Boese, and J. M. Weber, J. Chem. Phys. 123, 084307 (2005).

[33] G. S. Shafai, S. Shety, S. Krishnamurty, and D. G. Kanhere, J. Chem. Phys. 126, 014704 (2007).

[34] M. M. Mano, and C. R. Klime, Logic and Computer Design Fundamentals (Pearson Prentice-Hall, Upper Saddle River, 2008).

[35] C. M. Tesch, and R. D. Vivie-Riedle, J. Chem. Phys. 121, 12158 (2004).

[36] U. Troppmann, and R. de Vivie-Riedle, J. Chem. Phys. 122, 154105 (2005).

[37] D. Babikov, J. Chem. Phys. 121, 7577 (2004).

[38] M. Ndong, D. Lauvergnat, X. Chapuisat, and M. Desouter-Lecomte, J. Chem. Phys. 126, 244505 (2007).

[39] P. Liljeroth, J. Repp, and G. Meyer, Science 317, 1203 (2007).

[40] F. E. Olsson, S. Paavilainen, M. Persson, J. Repp, and G. Meyer, Phys. Rev. Lett. 98 (2007).

[41] J. Repp, G. Meyer, F. E. Olsson, and M. Persson, Science 305, 493 (2004).

[42] J. Repp, G. Meyer, S. Paavilainen, F. E. Olsson, and M. Persson, Science 312, 1196 (2006).

[43] T. M. Bernhardt, J. Hagen, L. D. Socaciu-Siebert, R. Mitrić, A. Heidenreich, J. L. Roux, D. Popolan, M. Vaida, L. Wöste, V. Bonačić-Koutecký, and J. Jortner, ChemPhysChem 6 (2005).

[44] R. Mitrić, M. Hartmann, B. Stanca, V. Bonačić-Koutecký, and P. Fantucci, J. Phys. Chem. A 105, 8892 (2001).

[45] L. D. Socaciu-Siebert, J. Hagen, J. L. Roux, D. Popolan, M. Vaida, S. Vajda, T. M. Bernhardt, and L. Wöste, Phys. Chem. Chem. Phys. 7, 2706 (2005).

[46] S. Wolf, G. Sommerer, S. Rutz, E. Schreiber, T. Leisner, L. Wöste, and R. S. Berry, Phys. Rev. Lett. 74, 4177 (1995).

[47] S.-i. Ishiuchi, M. Sakai, Y. Tsuchida, A. Takeda, Y. Kawashima, M. Fujii, O. Dopfer, and K. Müller-Dethlefs, Angew. Chem. Int. Ed. 44, 6149 (2005).

[48] V. Balzani, A. Credi, and M. Venturi, Molecular Devices and Machines. A Journey into the Nano World (Wiley-VCH, Weinheim, 2003).

[49] M. Conrad, and K.-P. Zauner, Molecular Computing (MIT Press, Boston, 2003).

[50] M. A. Nielsen, and I. L. Chuang, Quantum Computation and Quantum Information (Cambridge University Press, Cambridge, 2000).

[51] J. Li, X. Li, H. J. Zhai, and L. S. Wang, Science 299, 864 (2003).

[52] E. S. Kryachko, and F. Remacle, Int. J. Quant. Chem. 107, 2922 (2007).

[53] A. Gill, Linear Sequential Circuits (McGraw Hill, New York, 1966).

[54] Z. Kohavi, Switching and Finite Automata Theory (Tata McGraw-Hill, New Delhi, 1999).

[55] M. J. Frisch, G. W. Trucks, H. B. Schlegel, G. E. Scuseria, M. A. Robb, J. R. Cheeseman, J. J. A. Montgomery, T. Vreven, K. N. Kudin, J. C. Burant, J. M.

Millam, S. S. Iyengar, J. Tomasi, V. Barone, B. Mennucci, M. Cossi, G. Scalmani, N. Rega, G. A. Petersson, H. Nakatsuji, M. Hada, M. Ehara, K. Toyota, R. Fukuda, J. Hasegawa, M. Ishida, T. Nakajima, Y. Honda, O. Kitao, H. Nakai, M. Klene, X. Li, J. E. Knox, H. P. Hratchian, J. B. Cross, C. Adamo, J. Jaramillo, R. Gomperts, R. E. Stratmann, O. Yazyev, A. J. Austin, R. Cammi, C. Pomelli, J. W. Ochterski, P. Y. Ayala, K. Morokuma, G. A. Voth, P. Salvador, J. J. Dannenberg, V. G. Zakrzewski, S. Dapprich, A. D. Daniels, M. C. Strain, O. Farkas, D. K. Malick, A. D. Rabuck, K. Raghavachari, J. B. Foresman, J. V. Ortiz, Q. Cui, A. G. Baboul, S. Clifford, J.

Cioslowski, B. B. Stefanov, G. Liu, A. Liashenko, P. Piskorz, I. Komaromi, R. L. 
Martin, D. J. Fox, T. Keith, M. A. Al-Laham, C. Y. Peng, A. Nanayakkara, M.

Challacombe, P. M. W. Gill, B. Johnson, W. Chen, M. W. Wong, C. Gonzalez, and J. A. Pople, Gaussian, Inc., Wallington, CT (2003).

[56] R. B. Ross, J. M. Powers, T. Atashroo, W. C. Ermler, L. A. Lajohn, and P. A. Christiansen, J. Chem. Phys. 93, 6654 (1990). 